\title{
Mechanochemical activation of natural clay minerals: an alternative to produce sustainable cementitious binders - review
}

\author{
Ilda Tole ${ }^{1}$ (D) $\cdot$ Karin Habermehl-Cwirzen ${ }^{1} \cdot$ Andrzej Cwirzen $^{1}$
}

Received: 6 June 2018 / Accepted: 3 April 2019 / Published online: 8 May 2019

(C) The Author(s) 2019

\begin{abstract}
Mechanochemical activation can be defined as a process able to induce structural disorder through intensive grinding. In certain conditions, it may increase the chemical reactivity of the processed material. The process is extensively utilized in extractive metallurgy, synthesis of nanocomposites or pharmacology. It is also considered an environmentally friendly alternative to activate kaolinitic clay avoiding high calcination temperature. This paper aims to give a comprehensive overview of the process, its evolution, process parameters and applications. The paper focuses on the mechanochemical treatment of natural clay minerals, aiming at their transformation into cementitious or pozzolanic materials. It provides a summarized review of the theories related to the mechanochemistry and discusses commonly used models. The paper also analyzes various key factors and parameters controlling the mechanochemical activation process. The optimization and control of the several factors, as the filling ratio, the grinding media, the velocity, the time of grinding, etc., can promote developments and new research opportunities on different fields of application. Examples of applications, with a special focus on mechanochemically activated clay minerals and their use as cementitious binders, are listed as well.
\end{abstract}

Keywords Mechanochemistry $\cdot$ Grinding $\cdot$ Mechanochemical activation $\cdot$ Clay minerals $\cdot$ Kaolin

\section{Introduction}

Mechanochemical activation (MCA) is a process able to induce structural disorder, amorphisation and increased chemical reactivity in the material treated by intensive grinding, (McNaught and Wilkinson 1997; Baláž et al. 2013). The MCA is a simple method to apply, especially when done by milling. The entire process is characterized by small energy requirements, low processing temperatures, and thus reduced costs, and increased environmental friendliness, (Baláž, 2000, 2008; Boldyrev 2006; Rescic et al. 2011).

In the book De Lapidus (On Stones), Theophrastus of Eresus (371-286 B.C.) did the first documented description of a process, which could relate to the MCA, (Takacs 2000). In

Editorial handling: J. Elsen

Ilda Tole

ilda.tole@1tu.se

1 Luleå tekniska universitet, Department of Civil, Environmental and Natural Resources Engineering, Division of Structural and Fire Engineering, Luleå, Sweden
1820, Michael Faraday reduced $\mathrm{AgCl}$ to $\mathrm{Ag}$ with a pestle and a mortar, which also simulated to a certain extent the MCA process, (Fox 1975; Baláž 2008; James et al. 2012; Baláž et al. 2013). At the end of the nineteenth century, Mathew Carey Lea discovered that application of mechanical forces and heat treatment decomposed to halogen and metal the halides of gold, silver, platinum, and mercury. The same components melt or sublime under heat action, (Fox 1975; Baláž 2000, 2008; Takacs 2004; Baláž et al. 2013).

Later, Clark and Rowan discovered, that milling in the solid state or applying a high pressure on certain compounds could produce the same effects in their structure, (Baláž 2000, 2008). Walter Kelley investigated grinding of bentonite and kaolinite, and formulated a theory including only a physical disintegration of the minerals followed by a decrease in the particle size. Alfred Perkins stated, that grinding induces also disorders in the crystal lattice structure, (Gregg et al. 1953; Garcia et al. 1991).

In 1938, Bowden and Tabor published results of their studies in tribology, focusing on the contact area between moving surfaces. Temperatures of over $700{ }^{\circ} \mathrm{C}$ were observed at the contact of solid substances exposed to 
friction, (Fox 1975; Bowden and Tabor 1939, 1966; Baláž 2000, 2008; Baláž et al. 2013). Hüttig (1943) determined that activated solid produced by grinding had a thermodynamically and structurally unstable arrangement of the lattice. Furthermore, the value of enthalpy and the Gibbs energy also increased in the activated solid, (Hüttig 1943; Tkácová 1989; Tkáčová et al. 1993).

In 1942, for the first time, Adolf Smékal used the term "mechanical activation". Otherwise, Wilhelm Ostwald was credited by some authors to classify mechanochemistry as one of the four sub-disciplines of chemistry, among thermochemistry, electrochemistry and photochemistry, each of which is based on a different type of the input energy, (Rose and Sullivan 1958; Juhász 1998a; James et al. 2012).

Leonard Austin determined that the MCA process occurs when quantitative changes related to the particle size of the material cause qualitative changes in the nature of the material, (Boldyrev et al. 1996; Hennart et al. 2009).

In 1959, Hiroshi Takahashi published results of his studies focusing on the dry grinding of pure kaolinite and natural clay. Disordered crystalline structures and increased amorphous phases were detected in the processed materials. The crystalline structure tended to be amorphous at different times of dry grinding, depending on the structural order of the original mineral unit layers, (Takahashi 1959a, 1959b).

Effects produced by high energy ball milling and mechanochemical activation could be important for different technological applications including for example materials engineering, waste treatment, mineral processing, agriculture, extractive metallurgy, construction technology, pharmacy, or the coal industry, (Baláž 2008).

The clay itself, which is the main scope of this review, is a commonly occurring and sustainable natural mineral used in several applications. For example, calcined kaolinitic clays are widely used to manufacture pozzolanic cement, (Ambroise et al. 1994; Sabir et al. 2001; Vizcayno et al. 2010; Souri et al. 2015; Sandström 2016). Metakaolin, which is produced by thermal calcination of kaolinitic clays, is used as a supplementary cementitious material in the production of concrete. It has good pozzolanic activity, can increase the concrete strength and improve the durability. Furthermore, the MCA showed to enhance pozzolanic activity of the natural kaolinitic clays, (Ambroise et al. 1994; Sabir et al. 2001; Vizcayno et al. 2010; Souri et al. 2015).

The main aim of this paper is to review and analyze various factors and process parameters affecting the efficiency of the MCA process especially when applied on clay minerals. The output of this analysis should enable to define a set of initial parameters leading to an effective activation of natural clay minerals.

\section{Process}

The MCA process can be defined as a sequence of four stressrelated events including: compression, shear (attrition), impact and collision. Each type of milling equipment use different combination of these various stresses, leading to different efficiency of the process, (Baláž 2000, 2008; Baláž et al. 2013; Delogu and Takacs 2018). The main objective of the MCA process is to transfer as much energy as possible, from the milling balls to the ground material. The accumulated energy will enhance the chemical reactivity of the processed materials through dislocations and induced defects, (Boldyrev 2006; Baláž et al. 2013). A number of various types of milling equipment can be used for the MCA including ball mill, planetary ball mills or ring mills, Fig. 1.

The planetary ball mills showed short processing times, safe handling and good reproducibility, (Baláž 2000, 2008; Baláž et al. 2013). In the planetary ball mill, the jar is attached to a disk that rotates around the central axis. At the same time, the jar rotates around its own axis. During grinding, the movement of the balls is dependent on several process parameters. For example, the increase of the revolution speed and/or the filling ratio of the jar are able to change the movement of the balls from a cascading regime to a cataracting one and finally to a rolling regime, Fig. 2, (Burmeister and Kwade 2013).

The repetitive occurrence of structural changes can lead to the co-crystallization of the nearby particles by decreasing the specific surface area and the surface free energy, as well as inducing shrinkage. Juhász and Opoczky (1990) described the so-called melt-bridges formation because of the cocrystallization initiated by the interpenetration of particles and by the consecutive creation of a thin liquid film on their surface. During fine grinding, mechanical effects, friction and plastic deformation provide the necessary energy to form the melt-bridges, similar to the high temperature sintering process.

Another phenomenon observed during the grinding process is the chemi-hesion, which could be defined as a chemical bond between two solid surfaces being sufficiently close to each other. The chemi-hesion occurs only due to the developing capillary pressure, which could partly explain why these forces act even between particles of the same crystallinity and composition. Combined chemi-hesion and surface dislocations promote chemical reactions and intergrowth between particles of different compositions. Polymorphic transformations can occur as well, (Juhász 1998a, 1998b; Baláž et al. 2013).

Concerning kaolinitic clay, which is the focus of this paper, the MCA process is able to split the hydrogen bonds between the adjacent kaolinite layers, (Frost et al. 2001, 2001). It causes structural modifications of the crystal structure by the rupture of O-H, Al-OH, Al-O-Si and $\mathrm{Si}-\mathrm{O}$ bonds. The presence of quartz appeared to accelerate 

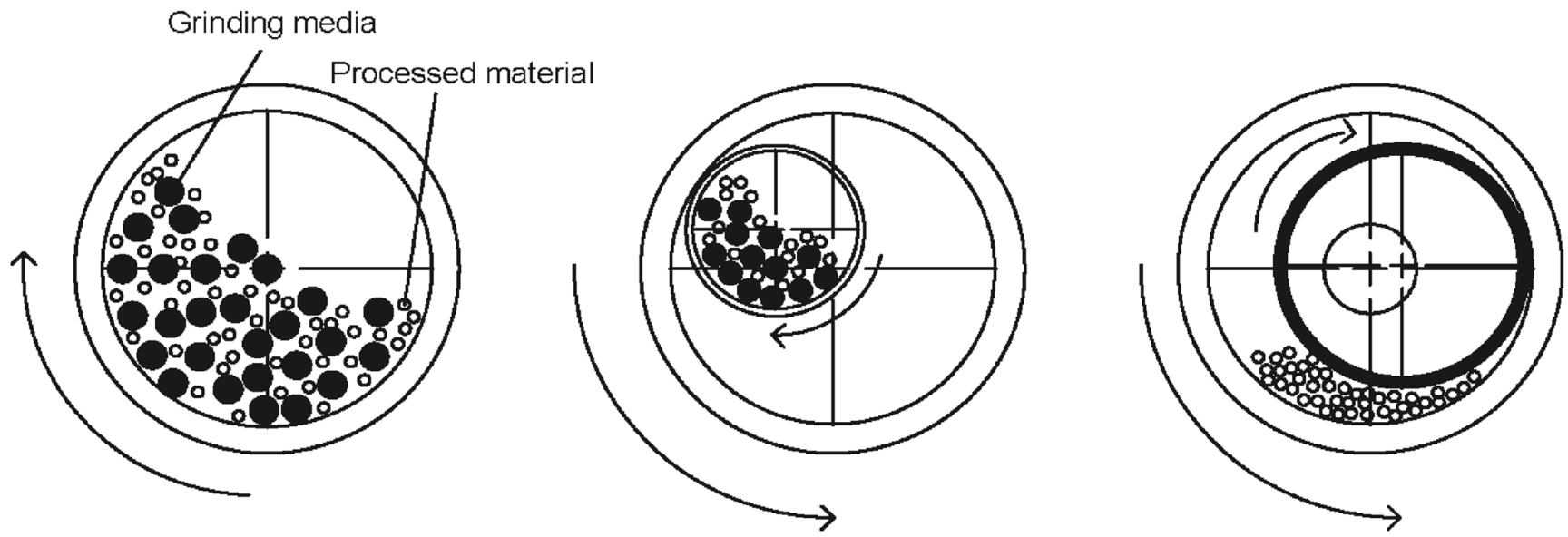

Fig. 1 Types of high energy milling equipment: 1- ball mill, 2- planetary ball mill, 3-ring mill

the amorphisation. The higher hardness of quartz particles allow them to act as a grinding media for the kaolinite particles, thus accelerating the grinding process, (Makó et al. 2001; Rescic et al. 2011; Hamzaoui et al. 2015). Results obtained by Sánchez et al. (1999) showed that mechanical milling of the kaolinite can generate a significant amount of Al surface in a tetrahedral coordination and can thus lead to a $20 \%$ decrease of the $\mathrm{Si} / \mathrm{Al}$ atomic ratio on the kaolinite surface. Structural amorphisation of kaolinite during repetitive grinding process has been detected through TEM and SEM analysis, respectively Figs. 3 and 4, and through X-ray diffraction analysis, Fig. 5. TEM and SEM micrographs show how the order of the structure is altered and replaced by amorphous regions.

Aglietti et al. (1986) observed physico-chemical changes while grinding kaolinite in an oscillating mill. The results showed that, at a certain stage, the ground material tends to agglomerate due to the high surface energy produced in the grinding process.

The adherence of the ground particles to the surface of the jar and of the grinding balls is defined as caking, or simply an adherence, and it interferes with the grinding process. The deposition of the first layer is followed by an accumulation of successive layers of material, which doesn't take part anymore in the grinding process, (Avvakumov et al. 2001).

Other studies showed, that the dehydroxylation temperature changes with the process duration, (Frost et al. 2003; Ding et al. 2012). The thermal analysis, Thermogravimetric analysis - TGA and Differential thermal analysis - DTA, showed a loss of hydroxyl groups from the kaolinite surface and their replacement with water molecules, (Frost et al. 2001, 2001). Amorphisation also appeared to destroy the bonds between the tetrahedral and the octahedral layers, (Takahashi

\section{Grinding media}

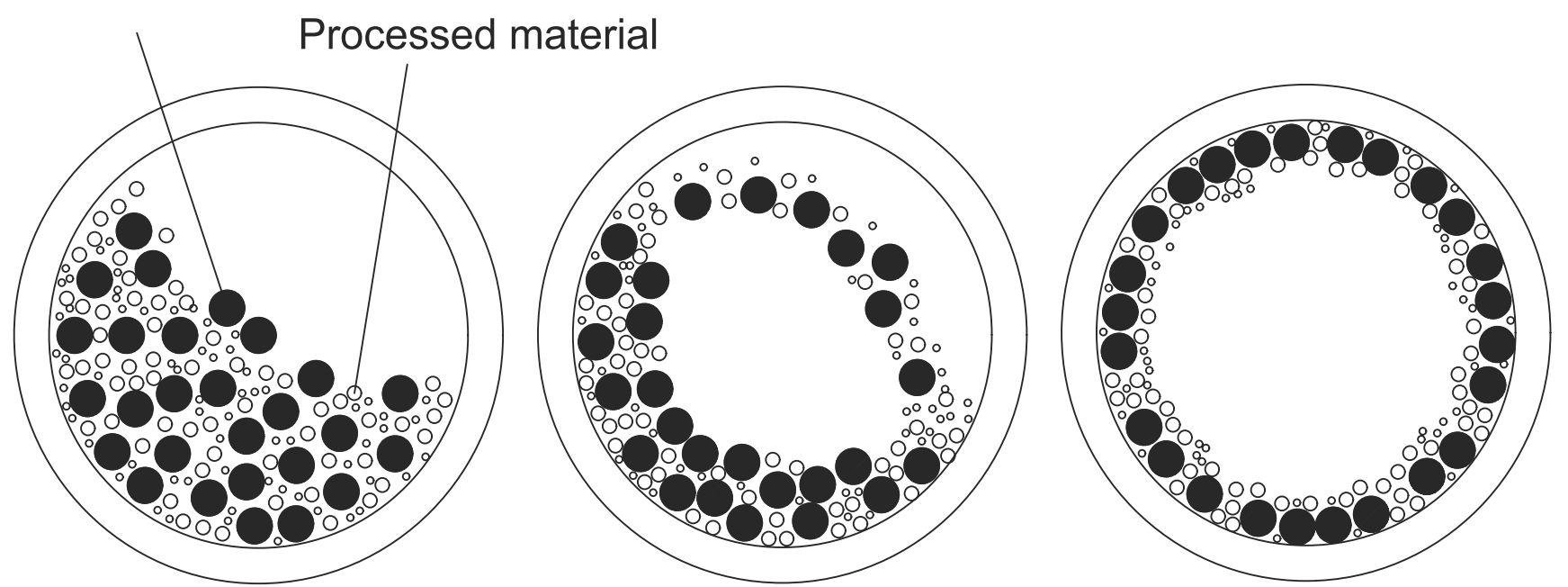

Fig. 2 Schematization of the milling ball motion in the jar of a planetary ball mill, respectively: cascading, cataracting, rolling 

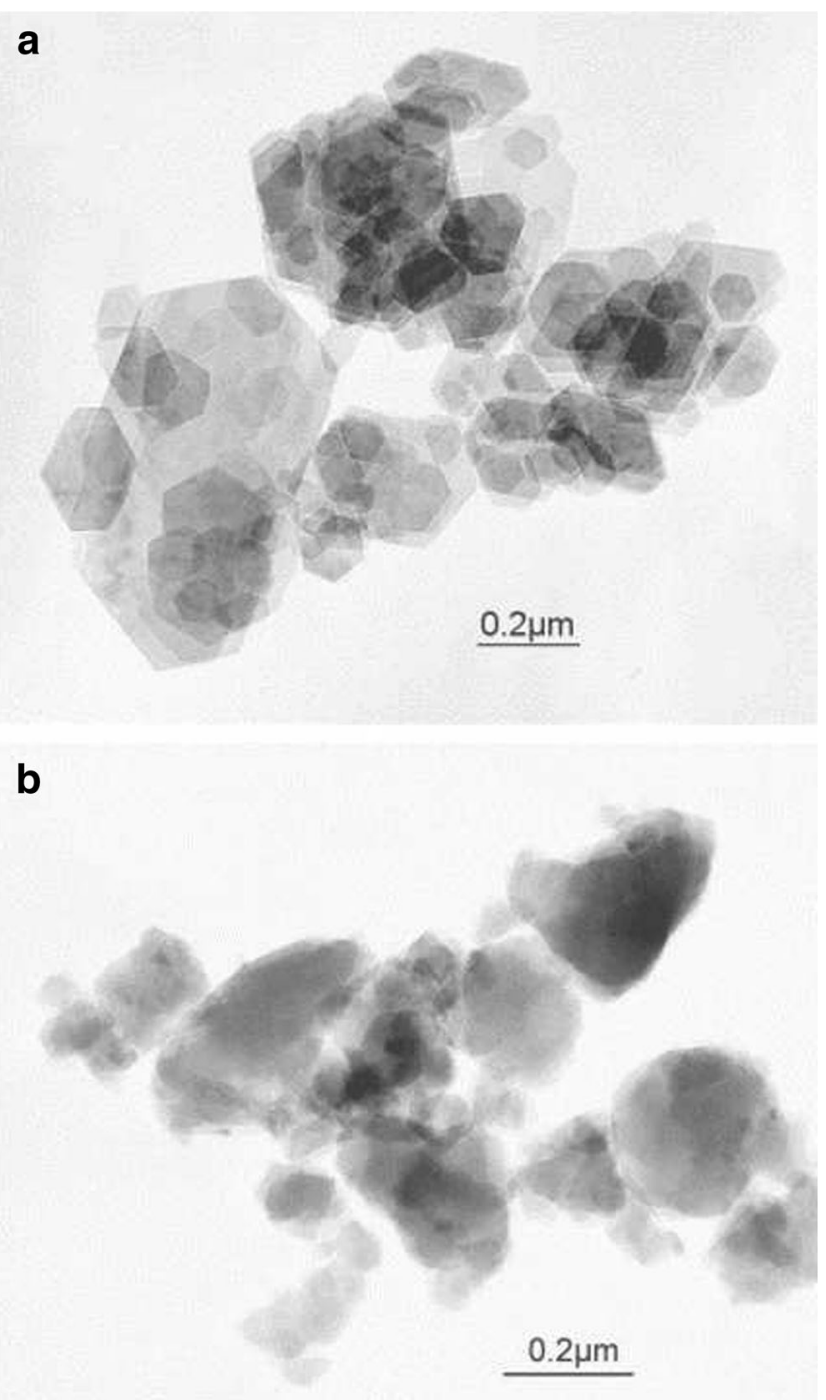

Fig. 3 TEM micrographs of the kaolinite/talc mixture with welldeveloped pseudo-hexagonal symmetry of kaolinite particles shown in Fig. 3a (unground) is replaced by amorphous, shapeless rounded aggregates after 60 min grinding in the ring mill in Fig. 3b, (Zbik and Smart 2005). Reprinted from Minerals Engineering, 18/9, Zbik M., Smart, R., Influence of dry grinding on talc and kaolinite morphology: inhibition of nano-bubble formation and improved dispersion, Pages 969-976, Copyright (2018), with permission from Elsevier

1959c). Grinding of kaolinite for up to $10 \mathrm{~h}$ reduced the crystallinity and increased the specific surface area, (Frost et al. 2001, 2001).

The X-ray Diffraction (XRD), the infrared spectroscopy (IR) and the DTA of kaolinite samples, performed after grinding, showed significantly altered structure, where the $\mathrm{OH}$ groups were removed from their positions and the tetrahedral and octahedral layers were distorted, (Kristof et al. 1993).

The MCA affected also other natural clay minerals, including for example, illite, (Yang et al. 2005), muscovite, montmorillonite, (Hrachova et al. 2007), or pyrophyllite, (Pi et al., 1988). Fragmentation of the clay minerals (e.g. montmorillonite, ripidolite or kaolinite) due to MCA caused the formation of new more reactive surfaces, (Vdovic et al. 2010).

A similar tendency related to structural changes was observed during grinding of talc and pyrophyllite. In these cases, dry grinding in a planetary ball mill deteriorated their structure, which became highly disordered, (Sugiyama et al. 1994). Fine grinding of talc has produced an altered and amorphous structure after less than $30 \mathrm{~min}$. As for the clay minerals, a particle size reduction associated with an increase in the specific surface area is obtained for MC activated talc, (Sugiyama et al. 1993; Sanchez-Soto et al. 1997).

MC processing of montmorillonite or kaolinite, in addition to decreased crystallinity and particle size, has shown interesting changes as e.g. creation of amorphous oxides of $\mathrm{Mg}$, increased content of $\mathrm{Fe}^{3+}$ cations compared to $\mathrm{Fe}^{2+}$ in processed montmorillonite, improvement of the DC conductivity in both kaolinite and montmorillonite, (Bekri and Sasra 2016; Ondruška et al. 2018).

Processing of bentonite by MCA led to the damage of the crystal structure and generated almost an amorphous material, especially when using long grinding times. The loss of crystallinity led to the formation of a solid silica gel, (Volzone et al. 1987).

Optimized process parameters can result in amorphized structure of clay minerals obtained already after $20 \mathrm{~min}$ of fine grinding, (Tole et al. 2018).

\section{Models}

One of the first models describing the MCA is the so-called hot-spot model proposed by Bowden and Tabor. It assumed that MCA occurs in micro-size areas of the contact zone due to friction phenomena. In these small areas, a local temperature could exceed $1300 \mathrm{~K}$ and last for $10^{-4}-10^{-3}$ seconds, causing the mechanically initiated reactions, (Bowden and Tabor 1939, 1966; Tkácová 1989; Baláž 2008).

Peter Thiesen developed the magma-plasma model, which considered the direct impact between two rough surfaces as the main process occurring during mechanochemical activation, Fig. 6, (Weichert and Schönert 1973).

The model assumed that local temperatures, higher than $10^{3} \mathrm{~K}$, can be generated at the impact points and can induce an excited state of the material. The high amount of energy can bring the processed solid to a plasmatic state, characterized by the formation and ejection of electrons, photons and excited fragments, (Tkácová 1989; Juhász 1998a, 1998b; James et al. 2012; Baláž et al. 2013).

Miller and Oulton observed that long and repeated processes of dry grinding creates greater stresses and structural changes in kaolin crystals in comparison with the thermal treatment. They also developed the theory of prototropy, which assumed 

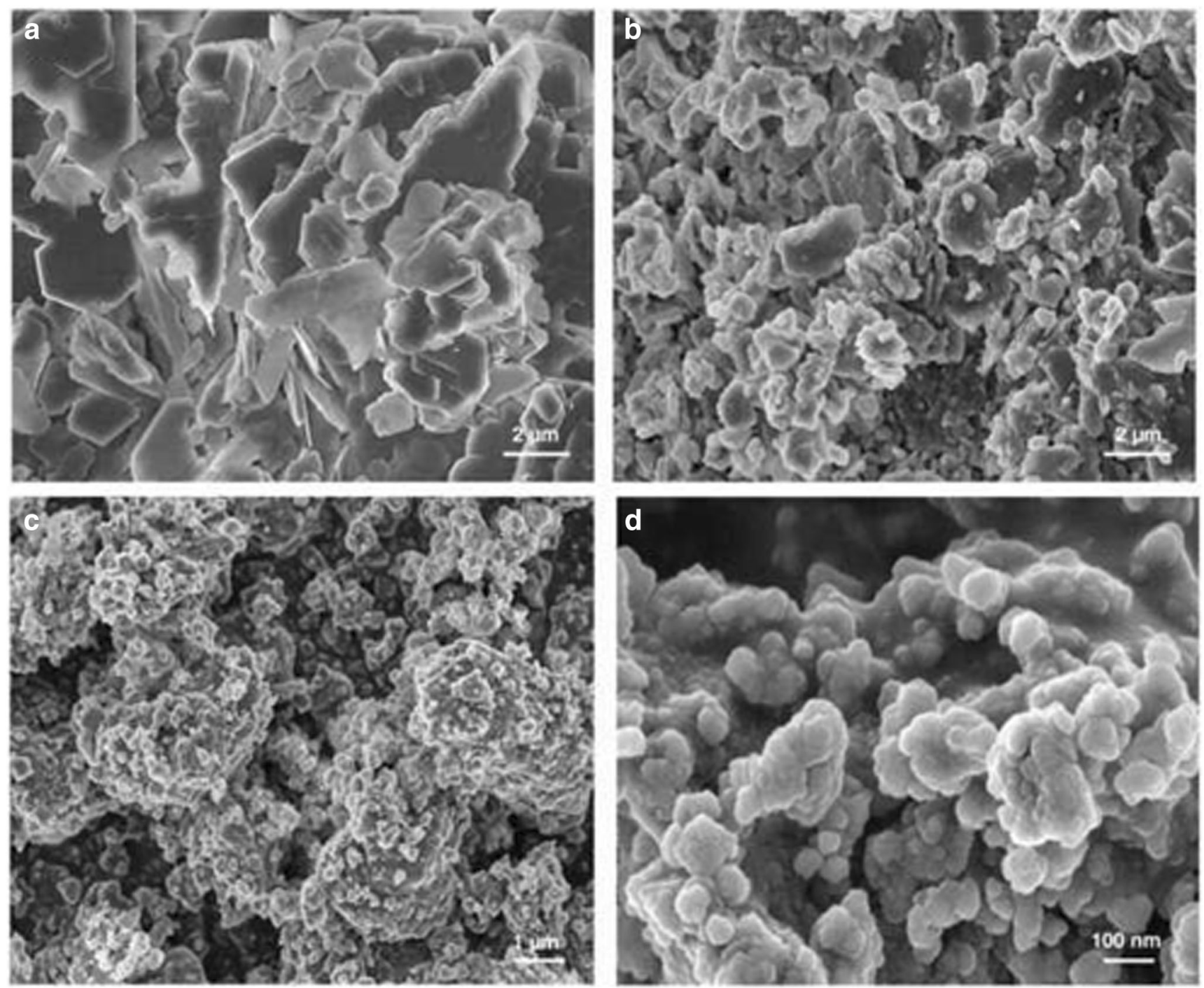

Fig. 4 SEM photomicrographs of kaolinite particles after HEBM for a 0 , b 16 and (c, d) $256 \mathrm{~min}$, (Vdovic et al. 2010). Reprinted from Applied Clay Science, 48/4, Vdović, N., Jurina, I., Škapin, S. D., Sondi, I., The

a possible migration of protons during grinding processes, thus enabling the interaction with $\mathrm{OH}$ groups and the consequently generation of water molecules. These molecules can be lost from the structure already at lower temperatures than required by the dehydroxylation process, (Miller and Oulton 1970; Mishirky et al. 1974; Garcia et al. 1991). The dehydroxylation process is defined as the elimination of water from the $\mathrm{OH}$ groups of minerals or inorganic compounds structures, and, in clay structures, it usually occurs at high temperatures between 400 and $800{ }^{\circ} \mathrm{C}$, (Vaughan 1955; Stoch and Wacławska 1981).

In 1974, Emmanuel Gutman showed another approach to explain the MCA process, through the so-called dislocation theory. The theory assumed that mechanical properties of a solid are related to the movement and interaction of dislocations. Increasing dislocations due to the mechanical action will surface properties of clay minerals modified by intensive dry milling revisited, Pages 575-580, Copyright (2018), with permission from Elsevier

enable their movement to the surface and transformation into areas with higher chemical activity, (Juhász and Opoczky 1990; Baláž, 2000, 2008; Baláž et al. 2013).

Boldyrev and Urakaev developed the kinetic model, which combines kinetics of the activation process with the kinetics of grinding. According to this approach, the MCA occurs due to the impulsive nature of temperature and pressure. The kinetic equation, which was also experimentally verified, described the evolution of the MCA process and effects of various parameters, as for example the rotation velocity, the number and size of the balls, mechanical properties of the balls and of the processed material, (Boldyrev et al. 1996; Urakaev and Boldyrev 2000a, 2000b).

Pavel Butyagin showed that during mechanochemical processes, the absorption of the elastic energy, high 


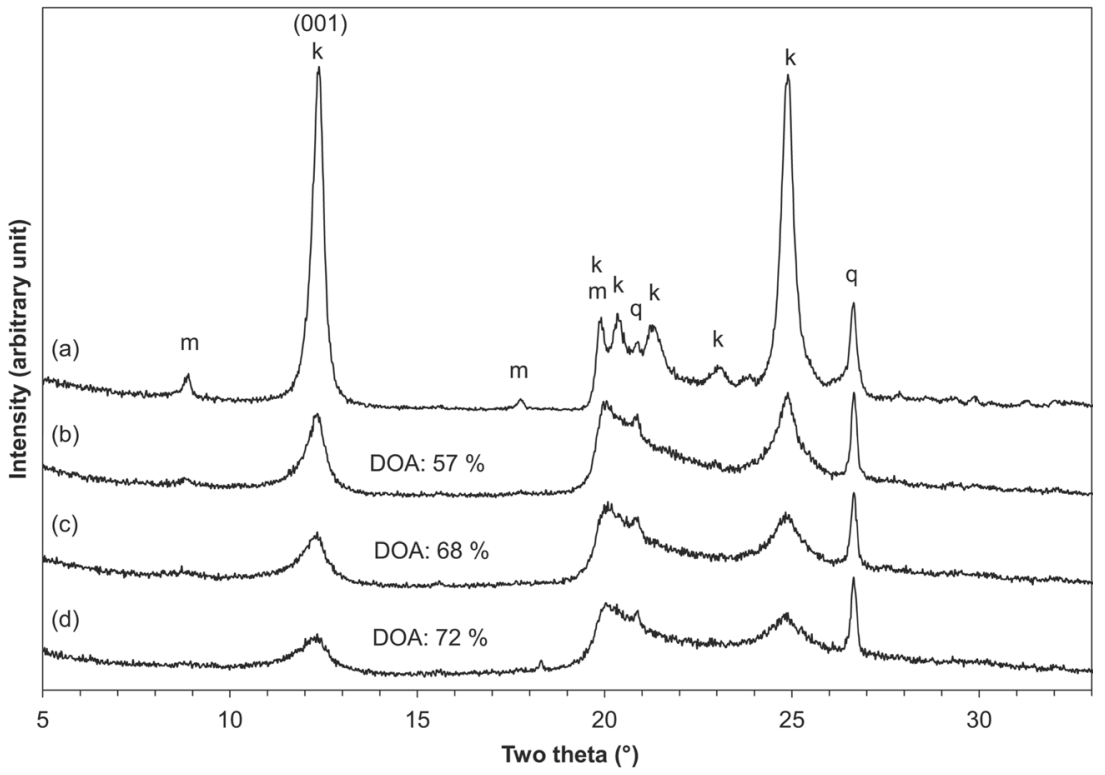

Fig. 5 XRD patterns of untreated kaolin a and of MA samples using $500 \mathrm{rpm}$, and $15 \mathrm{~min}$ grinding time as well as b 1:8, c 1:11, and $\mathbf{d}$ 1:14 ms:mgb values. (k: kaolinite PDF 14-164; m: muscovite PDF725; q: quartz PDF33-1161), (Balczár et al. 2016). Reprinted from

pressure and high temperature could supply a sufficient amount of energy for chemical reactions to occur, (Butyagin 1971; Boldyrev 2006; Baláž 2008).
Ceramics International, 42/14, Balczár, I., Korim, T., Kovács, A., Makó, É., Mechanochemical and thermal activation of kaolin for manufacturing geopolymer mortars - Comparative study, Pages 15367 15375, Copyright (2018), with permission from Elsevier

All the described models considered only one of the various energies related to MCA, while the phenomena are multiple and complex. For example, the hot-spot and the magma-

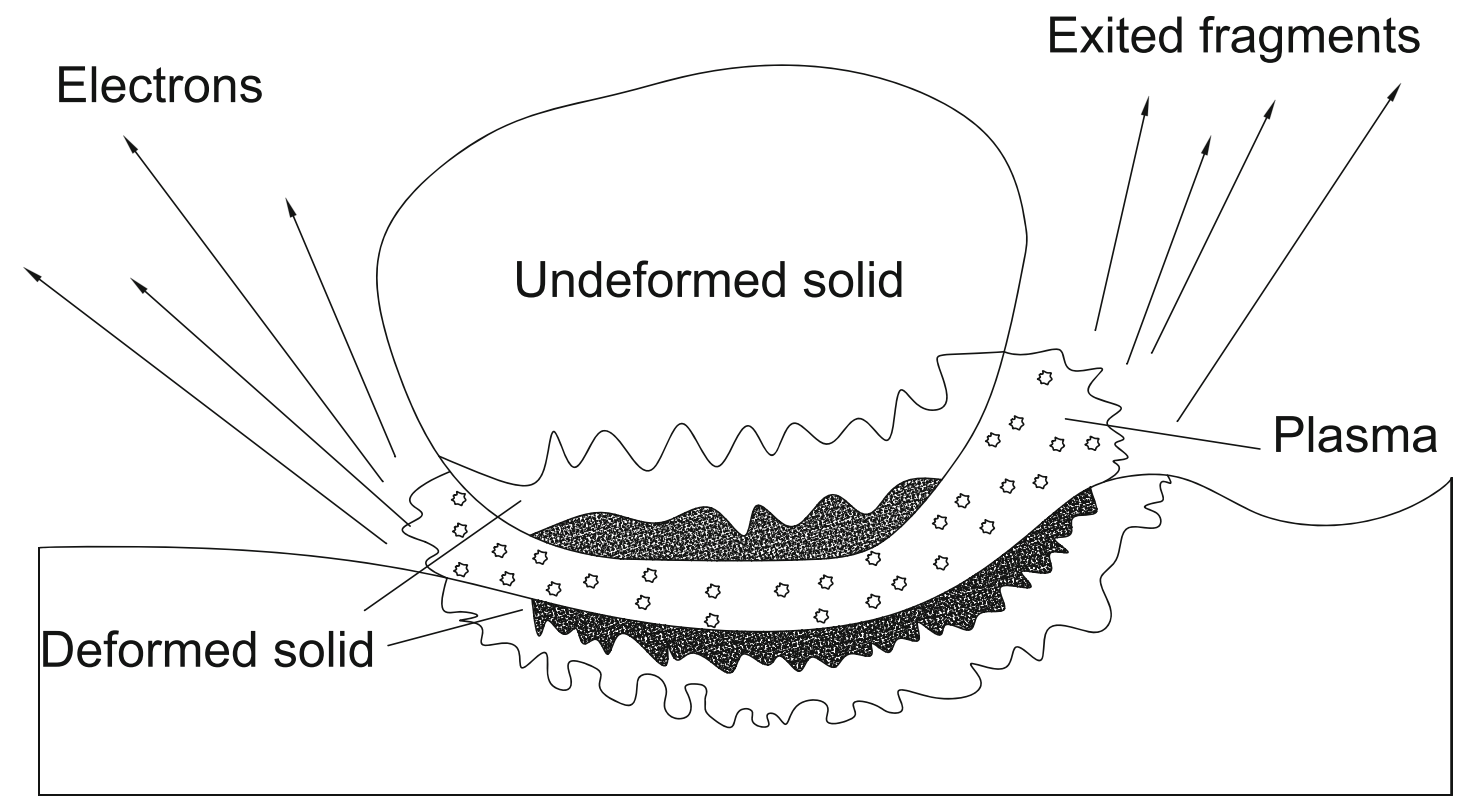

Fig. 6 Schematization of the magma-plasma model: S-solid not deformed, E-exited fragments and electrons, P-plasma, DS-highly deformed solid surface 
plasma model consider only high temperatures generated during the impact or in the contact zone, the dislocation theory considers that evolution of the process is only related to the dislocation movement. The kinetic model takes into account only the time of the process, (Juhasz and Opoczky 1990; Baláž 2008; Delogu and Cocco 2008).

One first attempt to unify the models and to better explain the MCA reactions was done by Tkáčová et al. (1989). The main conclusion was that the energy concentrates at the tip of the propagating crack, which results in creation of extreme conditions favorable for the MCA. These reactions were also assumed to be initiated by an impulsive temperature and pressure increase at the contact zones between the particles. The theory enables to explain the MCA process as being controlled by different effects: the dislocations movement, the contact zones rising temperature, high temperature and pressure with a pulse-type nature, and kinetics, (Tkačova et al. 1989).

Another approach illustrated by the so-called comminution theory was developed by Juhász and Opozcky (1990). The comminution is identified as a repetitive breakage occurring during grinding, (Juhasz and Opoczky 1990; Juhász 1998a, 1998b). The MCA process develops in two distinctive stages. The first stage, the comminution, is characterized by an increase of the specific surface area, higher surface energy and accumulated micro deformations. The second stage is the actual mechanochemical activation, where the specific surface area and the size of the crystallites remain constant but the mechanical energy is acquired in the form of the excess energy, which induces defects of the crystal lattice, (Tkačova et al. 1989; Juhász 1998a, 1998b; Prokof'ev and Gordina 2012). According to Rittinger's law, the energy required for the comminution to occur is proportional to the produced new surface and it is determined by the energy required to stress the particle until its failure, (Fuerstenau and Abouzeid 2002). Results showed, that up to $50 \%$ of the input energy could be transformed into strain, (Rumpf 1973; Tkáčová et al. 1993). According to the comminution theory, the rupture of the particles starts from the weakest points such as existing defects, dislocations or micro-cracks on the surface of the original material. During grinding and with the increasing dispersion degree, the particles become smaller. Moreover, the weak points have the tendency to move to the surface of the solid processed substance, (Rumpf 1973; Juhász 1998a, 1998b). The accumulation of defects and dislocation on the boundary layer at the particle surface can lead to the annihilation of dislocations.

This could act as an energy barrier with either increased or decreased load. The increased load would block further movements. Eventually, the developed high energy can cause plastic deformation, polymorphic transformations and amorphisation, (Juhász 1998a, 1998b).
The effects of the milling balls during the MCA are considerably different from those in the simple comminution process. Which is due to the effect of the reaction threshold energy, (Shinozaki and Senna 1981). The threshold effect is directly dependent on the initial impact stresses transmitted to the particles from the grinding device. Consequently, occurrence and development of the MCA process is strongly controlled by the process parameters of the grinding device, (Tkačova et al. 1989; V. Boldyrev et al. 1996).

Kinetics of reactions are rather complex due to the variability of the process conditions. The process is not homogeneous in terms of time and space, due to the pulse-type interaction between the grinding balls and the ground material. A model created by Avvakumov et al. (2001) distinguishes three main stages of the MCA process, Fig. 7.

The first stage implicates the fragmentation of the material and the gradual increase of the specific surface area. In the second the so-called dispersion stage, the formation of secondary particles or secondary aggregates dominates. The secondary aggregates are formed during the grinding process, through the agglomeration of fine particles, (Tkácová 1989). The third stage is characterized by the amorphisation and the simultaneous crystallization of new phases. This third stage continues until a stationary state is reached. The stationary state is directly dependent on the amount of mechanical energy. At a low energy level, the process can only continue until the first process stage. The second and the third stages can be reached only if the energy is sufficiently high, (Tkácová 1989; Avvakumov et al. 2001).

\section{Process parameters}

The most important parameters controlling the amorphisation process are the rate of stress and the efficiency of the energy transfer in the mill, (Tkáčová et al. 1993). MC-activated kaolinite in both planetary ball mill and high power ring mill has showed structural disorder during dry grinding process, Fig. 8.

SEM micrographs analysis showed, that different grinding durations influenced the structural changes of kaolin differently from each other and from the thermally treated one, Fig. 9.

The choice of process parameters determined the final structural order and influenced the duration of grinding. The duration is a crucial factor affecting the amorphisation of the structure. Ring and ball mills are also used to produce fine powders where the amorphisation of the structure should be avoided. For example, the preparation of samples for quantitative analysis of minerals with XRD technique. For this technique, wet grinding for very short duration, around $5 \mathrm{~min}$, can be used. The grinding medium is usually water, methanol or hexane. (Środoń 2006).

In the case of ball mills, the degree of mechanochemical transformation, $\alpha$, is a function of the rotational frequencies 
Fig. 7 Evolution and reaction of the particles during the mechanochemical activation process, Avvakumov model

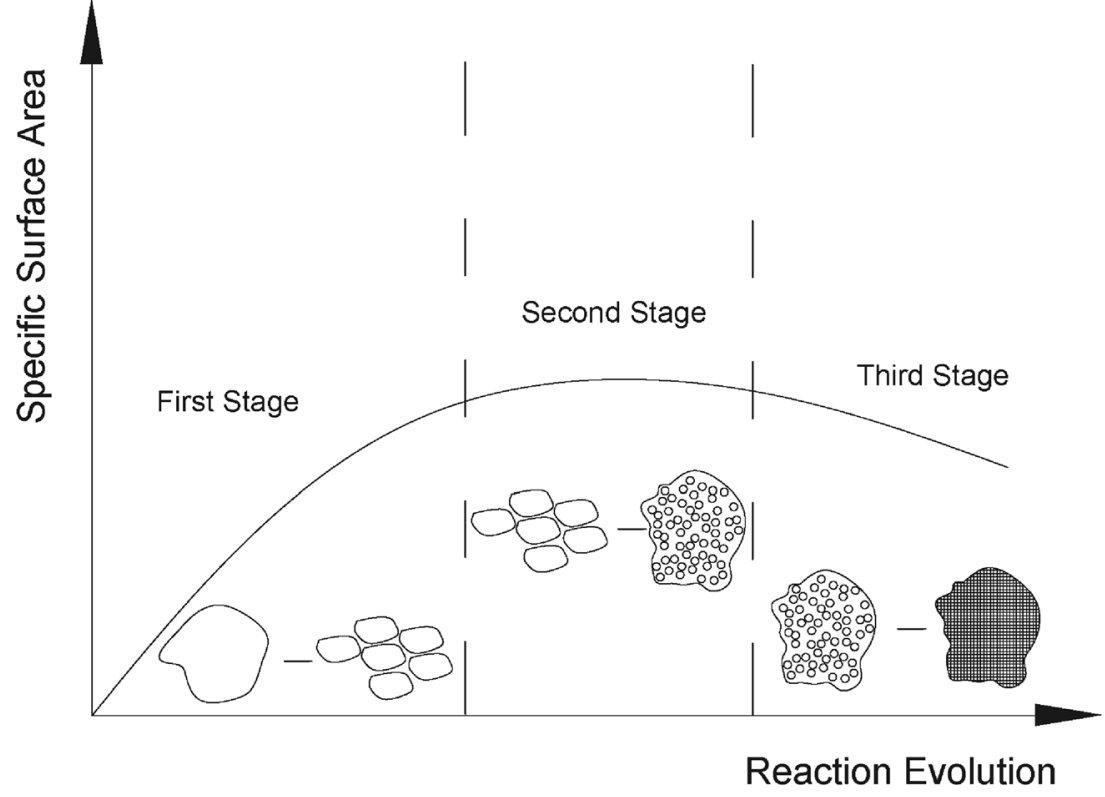

$\omega_{k}$, the number of milling balls $N$, the ratio $\left(R / l_{m}\right)$ of the ball size $R$ to the diameter of the jar $l_{m}$, the material properties of milling ball and compounds to be treated $X$, and the time $\tau$ of mechanical treatment, (Urakaev and Boldyrev 2000a, 2000b):

$\alpha=\alpha\left(\omega_{k}, N, R / l_{m}, X, \tau\right)$

The initial particle size distribution of the processed material tends to influence the development of the mechanochemical reactions and the kinetics of the process. Delogu and Takacs (2018) detected an exponential grain size reduction during grinding of powders having particle size distribution in the micrometer range. A gradual increase was also observed when grinding nanosized powders. Creation of melt-bridges and interpenetration of particles are considered to cause the grain growth. Consequently, a high particle size distribution may require more time for the MCA to occur, while the nanosize particle distribution can lead to agglomeration and mechanical alloying, (Juhász and Opoczky 1990; Delogu and Takacs 2018).

Juhász and Opoczky (1990) developed a theoretical correlation between changes of the specific surface area and the grinding time, distinguishing three different zones, Fig. 10.

(1) The Rittinger zone, where the growth of the specific surface area is proportional to the grinding time and the interaction mechanism of the particles is not considered.

(2) The Aggregation zone, where new produced surface areas are not proportional to the input energy and the particles aggregation is bonded by the Van der Waals forces.

(3) The Agglomeration zone, where the specific surface area decreases and the particles are chemically bonded together. The agglomeration can be also induced by moisture originating from the processed material, which can be counteracted by the addition of various types of dispersive agents, (Orumwense and Forssberg 1992). Agglomerates can be dispersed by a brief peptisation re-grinding which consists of a short-term wet re-grinding, (Tkácová and Stevulova 1987; Tkáčová et al. 1993). The grinding process tends to be easier if done in a wet environment where water or alcohol are commonly used. The wet grinding can reduce the agglomeration but can also increase the shrinkage of the material during the drying, and can promote cracks and deformations, (Rose and Sullivan 1958; Bond 1975; El-Shall and Somasundaran 1984; Juhász and Opoczky 1990). In general, the dry grinding appeared to be more effective than the wet grinding to impose significant structural amorphisation, (Takahashi 1959c; Juhász and Opoczky 1990).

The total impact energy tends to increase at higher rotational speeds, but at the same time, the grinding balls tend to attach to the inner walls of the grinding jar and to move in a rolling pattern. It results in a disappearance of the impact forces, Fig. 2, (Suryanarayana 2001; Ashrafizadeh and Ashrafizaadeh 2012).

A high grinding speed can also lead to increased temperature in the grinding jar. Therefore, the determination of the optimum rotational speed is crucial to enable the development of the maximum collision energy, (Suryanarayana 2001). Another parameter, which seems to affect the efficiency of the grinding process, is the grinding ball to powder ratio. 
Increasing of this ratio tends to increase the mass of the system and its kinematic energy. The collision probability will be higher but will also result in a greater amount of abrasion and contamination of the final product, (Ashrafizadeh and Ashrafizaadeh 2012). The free volume value of the grinding jar has to provide a sufficient space for the material to move during the grinding process.

Usually, the filling degree should not exceed $50 \%$ of the entire volume, (Suryanarayana et al. 2001). Examples of commonly used ratios are shown in Table 1.

The optimum range usually varied between 7:1 and 20:1, (Orumwense and Forssberg 1992), but others also used more extreme ratios of 1:1 up to 220:1, (Suryanarayana et al. 2001).

The efficiency of mechanochemical activation is also affected by the used grinding media, material density, particle shape and size, as well as by the overall system viscosity. In general, the grinding media should have a higher hardness of at least 3 Mohs than the ground material. They should be also
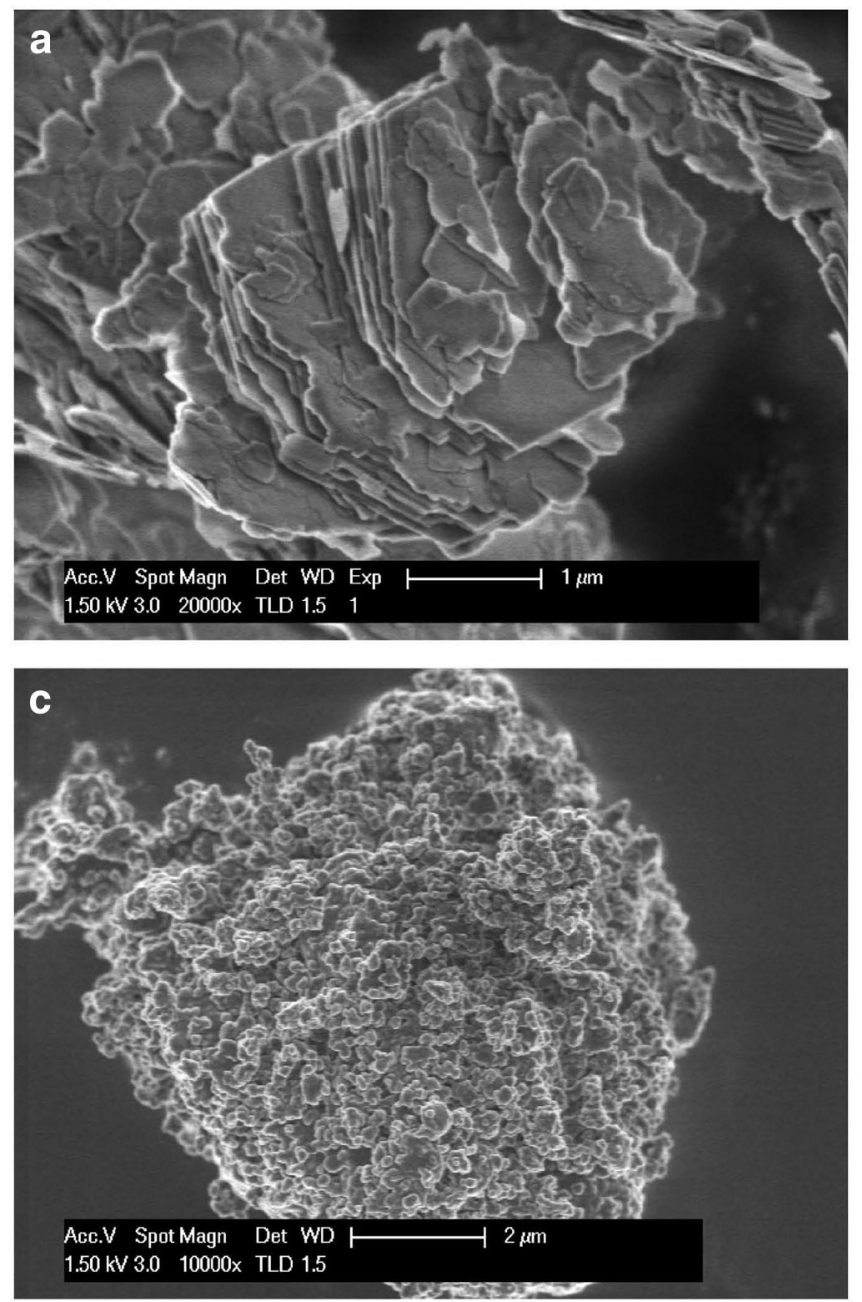

Fig. 8 SEM micrographs. (a and b) Unground kaolinite crystals; (c and d) amorphous, pulverized aggregates of nano-sized particles after $60 \mathrm{~min}$ grinding in the ring mill. (Souri et al. 2015). Reprinted from Cement and Concrete Research, 77, Souri, A., Kazemi-Kamyab, H., Snellings, denser than the processed material and chemically inert, (Orumwense and Forssberg 1992).

Milling balls with a higher density or large diameter produce higher impact energy during the collision, which results in a more effective surface activation. Smaller milling balls provide higher frictional forces and thus are useful for amorphisation or the formation of metastable phases, (Suryanarayana 2001). Typically, grinding balls are made of stainless steel, special metals, corundum, zirconia, carbides, etc., (Suryanarayana et al. 2001). A short list of various used ball sizes is shown in Table 2 .

Using water as a grinding medium enabled viscosity changes during the mechanochemical process in a ball mill, (Orumwense and Forssberg 1992). This effect can significantly influence the efficiency of the MCA. Diluted suspension can hinder the movement of the balls and thus decrease the impact forces transmitted to the processed material. On the other hand, an insufficient amount of water can enable to
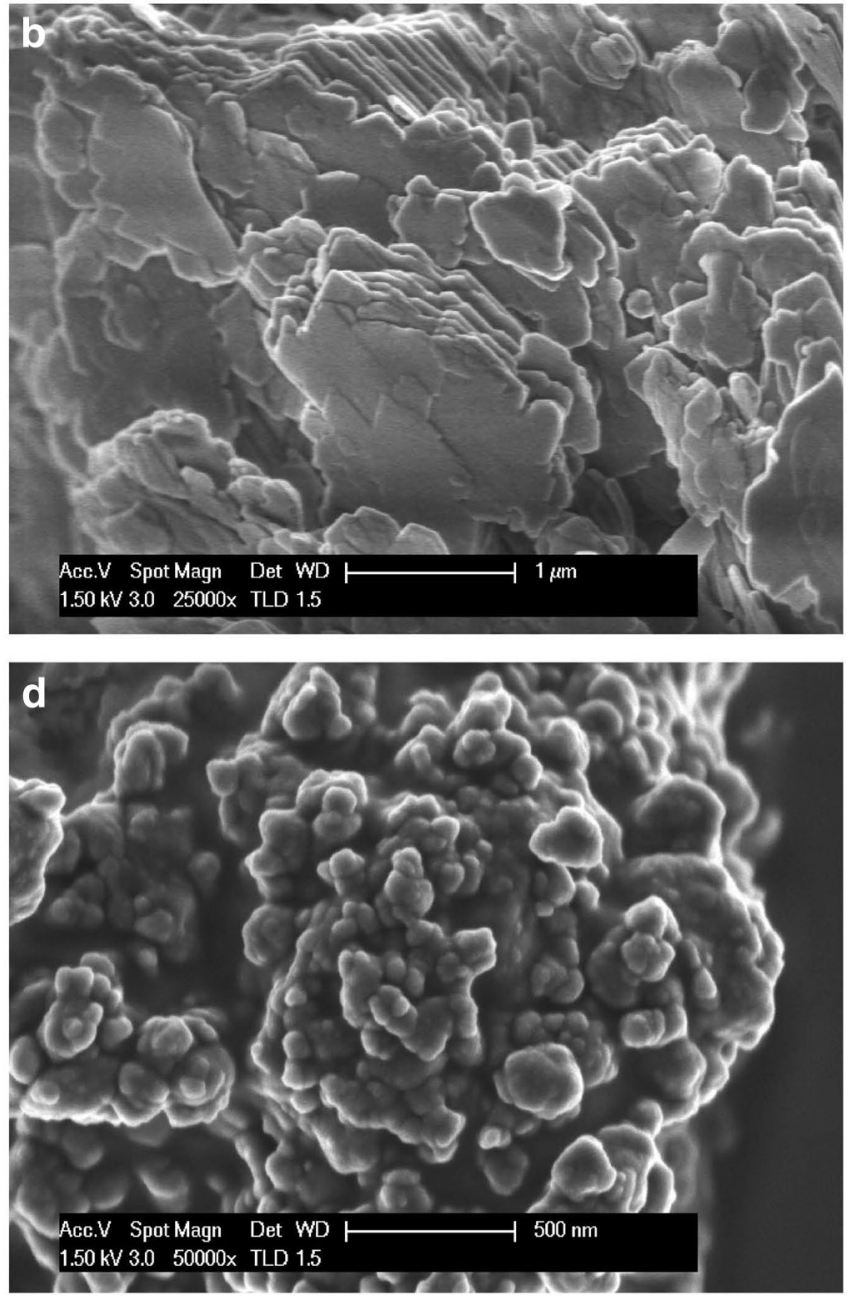

R., Naghizadeh, R., Golestani-Fard, F., Scrivener, K., Pozzolanic activity of mechanochemically and thermally activated kaolins in cement, Pages 47-59, Copyright (2018), with permission from Elsevier 

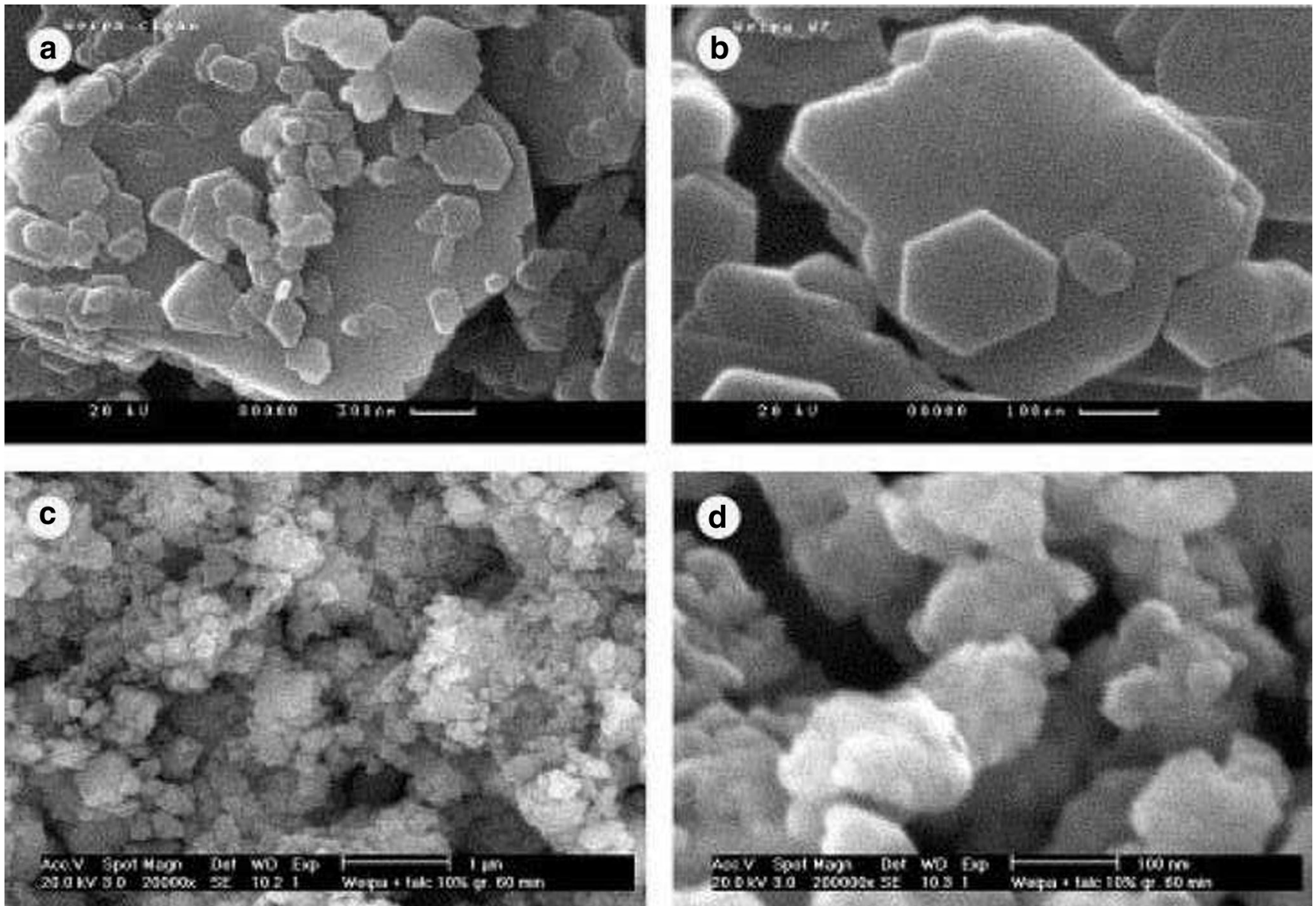

Fig. 9 SEM images of K_CZ kaolin a untreated, b heat treated at $700{ }^{\circ} \mathrm{C}$, c and $\mathbf{d}$ mechanochemically treated by $7 \mathrm{~h}$ of ball milling. (Zbik and Smart $2005)^{\mathrm{i}}$

obtain increased viscosity of the system during grinding. The powders became finer and the viscous system can literally block the movement of the grinding media in the jar, (Tole et al. 2018).

\section{Applications of mechanochemical activation}

Polymer Nanostructured Composites (PNC) can be produced by delamination of inorganic minerals through the mechanochemical treatment (MC). Clay minerals have been widely used as reinforcing fillers for polymeric matrixes to enhance their certain properties, (Lu et al. 2004; Yoshimoto et al. 2005; Perrin-Sarazin et al. 2009). MC treatments can modify the surface of clay powders and ameliorate their dispersion in the solid composite. The addition of $\mathrm{MC}$ treated clay minerals in the polymeric matrix showed lower gas permeability, higher thermal stability and improved mechanical properties of the PNC, (Yoshimoto et al. 2004, 2005; Hasegawa et al. 2007).

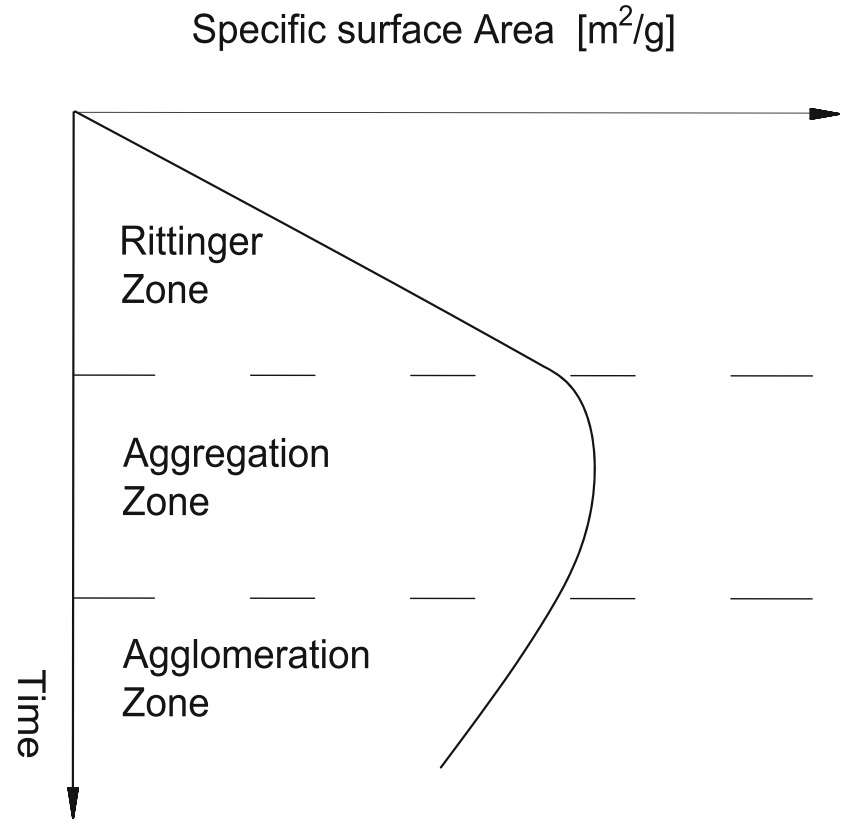

Fig. 10 Theoretical curve of specific surface as a function of grinding time 
Table 1 List of ball to powder ratio used in different experimental research

\begin{tabular}{lll}
\hline Author & Year & $\begin{array}{l}\text { Ball/Powder } \\
\text { ratio }\end{array}$ \\
\hline Frost. et al. & 2001 & $3: 1$ \\
Ebadzadeh & 2010 & $15: 1$ \\
Rescic et al. & 2011 & $50: 1$ \\
Mitrović et al. & 2012 & $25: 1$ \\
Mitrović et al. & 2014 & $10: 1$ \\
Souri et al. & 2015 & $25: 1$ \\
Hamzaoui et al. & 2015 & $3,1: 1$ \\
Balczár et al. & 2016 & $8: 1,11: 1,14: 1$ \\
\hline
\end{tabular}

The simultaneous dry grinding of kaolin and solid urea mixtures can lead to the mechanochemical intercalation. The intercalation process allowed creation of guest urea molecules in the unfilled space of the kaolinite structure. The formed nanostructured complexes can be suitable to be uses as reinforcement in clay-polymer nanocomposites, (Makó et al. 2009).

MCA of phosphates together with kaolinite is used to produce slow-release fertilizers. As mentioned before, fine grinding of clay minerals is able to produce nanosized reactive materials. These processed minerals are capable to retain certain elements such as for example potassium followed by their subsequent slow release, (Zhang et al. 2011; Borges et al. 2015).

Toxic and non-biodegradable heavy metals present in wastewaters are usually produced by mining and metal industries. The adsorption process is considered a simple and effective treatment for their removal, (Jiang et al. 2010; Fu and
Wang 2011; Kumrić et al. 2013). Bentonites and kaolins were found to be efficient in removing fluoride or divalent heavy metals by sorption, (Meenakshi et al. 2008; Kumrić et al. 2013). The MC treatment appeared to decrease the structural order and to increase the specific surface area of clays. The present phenomena including fragmentation of the particles, abrasion, and amorphisation, can lead to a higher cation exchange capacity and thus to an improved sorption capability, (Jiang et al. 2010; Fu and Wang 2011; Djukić et al. 2013).

Cement and concrete are considered to be irreplaceable construction materials. A very high carbon dioxide footprint of Portland cement puts an increasing pressure on the industry to mitigate this negative feature. Increasing the availability of concrete is at the present strongly connected with an effort to reduce its negative environmental impact due to a high carbon dioxide footprint, (Scrivener 2014). Now, two approaches are used, modernization of the production technology of the Portland cement and limiting of its content in a typical concrete. The cement content can be reduced by optimizing the mix design, increasing its reactiveness (Elfgren et al. 2004) or replacing by pozzolanic materials. Typically used pozzolanic materials include fly ash, slag and natural pozzolans, are considered a fast short-term countermeasure to reduce $\mathrm{CO}_{2}$ emission, (Scrivener 2014). On the other hand, the research aiming to develop new cements or SCM is limited by the availability of different elements constituting the earth's crust, (Scrivener 2014). Clay is a commonly occurring material, and the use of limestone and calcined clay to replace up to $50 \%$ of clinker in concrete has shown good results in reducing the $\mathrm{CO}_{2}$ emission, (Fernandez et al. 2011; Scrivener 2014; Joseph et al. 2015; Vizcaíno et al. 2015). However, high carbon dioxide emitting thermal activation method through calcination of kaolin is by far the main way to obtain metakaolin characterized
Table 2 List of ball size diameter used in different grinding regime, in experimental research

\begin{tabular}{lll}
\hline Author & $\begin{array}{l}\text { Ball size } \\
\text { diameter (mm) }\end{array}$ & Material \\
\hline Pérez-Rodriguez et al. (1988) & 20 & Pyrophyllite \\
Garcia et al. (1991) & 16 and 18 & Kaolin \\
Sugiyama et al. (1993) & 15 & Pyrophyllite and talc \\
Kristóf et al. (1993) & 7 & Kaolin \\
Sugiyama et al. (1994) & 16 & Pyrophyllite and Kaolin \\
Frost et al. (2001) & 10 & Kaolin \\
Yang et al. (2005) & 10 and 20 & Illite \\
Koc et al. (2011) & 100 & Kaolin \\
Valášková et al. (2011) & 13 & Kaolin \\
Ding et al. (2012) & 3,5 and 8 & Kaolin \\
Mitrović and Zdujić (2014) & 20 to 60 & Clay \\
Souri et al. (2015) & 10 & Kaolin \\
Hamzaoui et al. (2015) & 30 & Kaolin \\
Balczár et al. (2016) & 10 & Kaolin \\
\hline
\end{tabular}


by a sufficient pozzolanic activity. An alternative solution is to use MCA, (Vizcayno et al. 2010; Mitrović and Zdujić 2012, 2014; Souri et al. 2015; Balczár et al. 2016; Ilić et al. 2016). Souri et al. (2015) observed that both treatments, thermal and mechanochemical, led to the formation of pozzolanic materials, but are characterized by different physico-chemical properties.

Results showed that the increased specific surface area of the mechanochemically processed kaolin enhanced the early age hydration speed and the strength development of blended cements, (Souri et al. 2015). The intensive grinding produced a strong structural alteration of the silicates. It increased the specific surface area and decreased the particle size. Furthermore, grinding showed a progressive amorphisation and formation of agglomerates, (Sanchez-Soto et al. 1994, 2000).

Mechanochemical treatment of kaolinitic clay with a high quartz content produced materials having a very high pozzolanic activity, especially at an early stage due to the amorphisation, (Vizcayno et al. 2010). Using the MCA on clays rich in montmorillonite or illite also lead to the formation of a reactive material. Despite, their lower 28-days strength these materials could be still used in certain engineering applications, (Murat and Comel 1983; Murat 1983a, 1983b; Ambroise et al. 1985; Yang et al. 2005). The MCA activated kaolinite was also successfully used to produce geopolymers, (Davidovits 1991; Provis and Bernal 2014; Balczár et al. 2016).

\section{Conclusions}

The MCA can be considered an ecologically friendly technique, which can contribute to reduce the $\mathrm{CO}_{2}$ emissions by replacing some currently thermally intensive processes. Processing of commonly available raw materials, including natural materials as well as industrial wastes, with MCA should enable the development of a new generation of environmentally friendly and construction sustainable materials. The tailor optimized MCA process could be a valuable instrument to produce active natural clay, which could replace partly or completely the Portland cement in the production of concrete.

However, the literature study performed in this review showed a number of areas, which must be further investigated, including the MCA process itself, effects of various process parameters on produced materials, and its behavior in hydration or geopolymerisation processes.

Acknowledgements The authors would like to acknowledge the Swedish research council Formas for funding and supporting the "ClayCem" project.
Open Access This article is distributed under the terms of the Creative Commons Attribution 4.0 International License (http:// creativecommons.org/licenses/by/4.0/), which permits unrestricted use, distribution, and reproduction in any medium, provided you give appropriate credit to the original author(s) and the source, provide a link to the Creative Commons license, and indicate if changes were made.

\section{References}

Aglietti E, Lopez JP, Pereira E (1986) Mechanochemical effects in kaolinite grinding. I textural and physicochemical aspects. Int J Miner Process 16(1-2):125-133

Ambroise J, Murat M, Pera J (1985) Hydration reaction and hardening of calcined clays and related minerals $\mathrm{V}$. extension of the research and general conclusions. Cem Concr Res 15(2):261-268

Ambroise J, Maximilien S, Pera J (1994) Properties of metakaolin blended cements. Adv Cem Based Mater 1(4):161-168

Ashrafizadeh H, Ashrafizaadeh M (2012) Influence of processing parameters on grinding mechanism in planetary mill by employing discrete element method. Adv Powder Technol 23(6):708-716

Avvakumov EG, Senna M, Kosova N (2001) Soft mechanochemical synthesis: A basis for new chemical technologies, Springer Science \& Business Media

Baláž P (2000) Extractive metallurgy of activated minerals (Vol. 10). Elsevier

Baláž, P. (2008). From minerals to nanoparticles. In Mechanochemistry in nanoscience and minerals engineering. Springer, Berlin, Heidelberg (pp. 177-256)

Baláž P, Achimovičová M, Baláž M, Billik P, Cherkezova-Zheleva Z, Criado JM, Gotor FJ (2013) Hallmarks of mechanochemistry: from nanoparticles to technology. Chem Soc Rev 42(18):7571-7637

Balczár I, Korim T, Kovács A, Makó É (2016) Mechanochemical and thermal activation of kaolin for manufacturing geopolymer mortarscomparative study. Ceram Int 42(14):15367-15375

Bekri-Abbes I, Srasra E (2016) Effect of mechanochemical treatment on structure and electrical properties of montmorillonite. J Alloys Compd 671:34-42

Boldyrev VV (2006) Mechanochemistry and mechanical activation of solids. Russ Chem Rev 75(3):177-189

Boldyrev VV, Pavlov SV, Goldberg EL (1996) Interrelation between fine grinding and mechanical activation. Int J Miner Process 44:181-185

Bond FC (January 1975) Crushing and grinding calculations: part I. Mining Congress J:38-40

Borges R, Brunatto SF, Leitão AA, De Carvalho GS, Wypych F (2015) Solid-state mechanochemical activation of clay minerals and soluble phosphate mixtures to obtain slow-release fertilizers. Clay Miner 50(2):153-162

Bowden FP, Tabor D (1939) The area of contact between stationary and moving surfaces. Proc R Soc Lond A 169(938):391-413

Bowden F, Tabor D (1966) Friction, lubrication and wear: A survey of work during the last decade. Br J Appl Phys 17(12):1521-1544

Burmeister CF, Kwade A (2013) Process engineering with planetary ball mills. Chem Soc Rev 42(18):7660-7667

Butyagin PY (1971) Kinetics and nature of mechanochemical reactions. Russ Chem Rev 40(11):901-915

Davidovits J (1991) Geopolymers: inorganic polymeric new materials. J Therm Anal Calorim 37(8):1633-1656

Delogu F, Cocco G (2008) Weakness of the "hot spots" approach to the kinetics of mechanically induced phase transformations. J Alloys Compd 465:540-546

Delogu F, Takacs L (2018) Information on the mechanism of mechanochemical reaction from detailed studies of the reaction kinetics. Journal of Materials Science, (pp. 1-12) 
Ding S, Zhang L, Ren X, Xu B, Zhang H, Ma F (2012) The characteristics of mechanical grinding on kaolinite structure and thermal behavior. Energy Procedia 16:1237-1240

Djukić A, Jovanović U, Tuvić T, Andrić V, Novaković JG, Ivanović N, Matović L (2013) The potential of ball-milled Serbian natural clay for removal of heavy metal contaminants from wastewaters: simultaneous sorption of $\mathrm{Ni}, \mathrm{Cr}, \mathrm{Cd}$ and $\mathrm{Pb}$ ions. Ceram Int 39(6):71737178

Ebadzadeh T (2010) Effect of mechanical activation and microwave heating on synthesis and sintering of nano-structured mullite. $\mathrm{J}$ Alloys Compd 489(1):125-129

Elfgren L, Jonasson JE, Ronin V (2004) High performance concretes with energetically modified cement (EMC). In International Symposium on Ultra High Performance Concrete (pp. 93-103)

El-Shall H, Somasundaran P (1984) Physico-chemical aspects of grinding: A review of use of additives. Powder Technol 38(3):275-293

Fernandez R, Martirena F, Scrivener KL (2011) The origin of the pozzolanic activity of calcined clay minerals: A comparison between kaolinite, illite and montmorillonite. Cem Concr Res 41(1):113-122

Fox P (1975) Mechanically initiated chemical reactions in solids. J Mater Sci 10(2):340-360

Frost RL, Horváth E, Makó É, Kristóf J, Cseh T (2003) The effect of mechanochemical activation upon the intercalation of a high-defect kaolinite with formamide. J Colloid Interface Sci 265(2):386-395

Frost RL, Mako E, Kristof J, Horvath E, Kloprogge JT (2001) Modification of kaolinite surfaces by mechanochemical treatment. Langmuir 17(16):4731-4738

Frost RL, Makó É, Kristóf J, Horváth E, Kloprogge JT (2001) Mechanochemical treatment of kaolinite. J Colloid Interface Sci 239(2):458-466

Fu F, Wang Q (2011) Removal of heavy metal ions from wastewaters: A review. J Environ Manag 92(3):407-418

Fuerstenau D, Abouzeid A (2002) The energy efficiency of ball milling in comminution. Int J Miner Process 67(1):161-185

Garcia G, Abrio MR, Rodriguez MG (1991) Effects of dry grinding on two kaolins of different degrees of crystallinity. Clay Miner 26(4): 549-565

Gregg S, Parker T, Stephens M (1953) The effect of grinding on kaolinite. Clay Minerals Bulletin 2:34-44

Hamzaoui R, Muslim F, Guessasma S, Bennabi A, Guillin J (2015) Structural and thermal behavior of proclay kaolinite using high energy ball milling process. Powder Technol 271:228-237

Hasegawa M, Kimata M, Takahashi I (2007) Mechanochemical polymerization of styrene initiated by the grinding of layered clay minerals. Adv Powder Technol 18(5):541-554

Hennart S, Wildeboer W, Van Hee P, Meesters G (2009) Identification of the grinding mechanisms and their origin in a stirred ball mill using population balances. Chem Eng Sci 64(19):4123-4130

Hrachová J, Komadel P, Fajnor VŠ (2007) The effect of mechanical treatment on the structure of montmorillonite. Mater Lett 61(16): $3361-3365$

Hüttig GF (1943) Zur systematik der aggregatzustände. KolloidZeitschrift 104(2-3):161-167

Ilić B, Radonjamin V, Malešev M, Zdujić M, Mitrović A (2016) Effects of mechanical and thermal activation on pozzolanic activity of kaolin containing mica. Appl Clay Sci 123:173-181

James SL, Adams CJ, Bolm C, Braga D, Collier P, Friščić T, Jones W (2012) Mechanochemistry: opportunities for new and cleaner synthesis. Chem Soc Rev 41(1):413-447

Jiang M, Jin X, Lu X, Chen Z (2010) Adsorption of Pb (II), Cd (II), Ni (II) and $\mathrm{Cu}$ (II) onto natural kaolinite clay. Desalination 252(1):33-39

Joseph S, Joseph AM, Bishnoi S (2015) Economic implications of limestone clinker calcined clay cement (LC 3 ) in India. In Calcined Clays for Sustainable Concrete (pp. 501-507). Springer, Dordrecht
Juhász AZ (1998a) Aspects of mechanochemical activation in terms of comminution theory. Colloids Surf A Physicochem Eng Asp 141(3): $449-462$

Juhász AZ (1998b) Colloid-chemical aspects of mechanical activation. Part Sci Technol 16(2):145-161

Juhász AZ, Opoczky L (1990) Mechanical activation of minerals by grinding pulverizing and morphology of particles. 1st edition, Ellis Horwood Limited, England. ISBN 0-7458-0015-7

Koç S, Toplan N, Yildiz K, Toplan HÖ (2011) Effects of mechanical activation on the non-isothermal kinetics of mullite formation from kaolinite. J Therm Anal Calorim 103(3):791-796

Kristóf E, Juhász AZ, Vassanyi I (1993) The effect of mechanical treatment on the crystal structure and thermal behavior of kaolinite. Clay Clay Miner 41(5):608-612

Kumrić KR, Đukić AB, Trtić-Petrović TM, Vukelić NS, Stojanović Z, Grbović Novaković JD, Matović LL (2013) Simultaneous removal of divalent heavy metals from aqueous solutions using raw and mechanochemically treated interstratified montmorillonite/kaolinite clay. Ind Eng Chem Res 52(23):7930-7939

Lu H, Liang G, Ma X, Zhang B, Chen X (2004) Epoxy/clay nanocomposites: further exfoliation of newly modified clay induced by shearing force of ball milling. Polym Int 53(10):1545-1553

Makó É, Frost RL, Kristóf J, Horváth E (2001) The effect of quartz content on the mechanochemical activation of kaolinite. J Colloid Interface Sci 244(2):359-364

Makó É, Kristóf J, Horváth E, Vágvölgyi V (2009) Kaolinite-urea complexes obtained by mechanochemical and aqueous suspension techniques - a comparative study. J Colloid Interface Sci 330(2): 367-373

McNaught AD, Wilkinson A (1997) IUPAC. Compendium of chemical terminology, 2nd ed. (the "gold book"). Oxford: Blackwell science

Meenakshi S, Sundaram CS, Sukumar R (2008) Enhanced fluoride sorption by mechanochemically activated kaolinites. J Hazard Mater 153(1):164-172

Miller JG, Oulton TD (1970) Prototropy in kaolinite during percussive grinding. Clay Clay Miner 18(6):313-323

Mishirky S, Yariv S, Siniansky W (1974) Some effects of grinding kaolinite with calcined kaolinite. Clay Sci 4(5):213-224

Mitrović A, Zdujić M (2012) Mechanochemical treatment of serbian kaolin clay to obtain a highly reactive pozzolana. J Serb Chem Soc 78(4):579

Mitrović A, Zdujić M (2014) Preparation of pozzolanic addition by mechanical treatment of kaolin clay. Int J Miner Process 132:59-66

Murat M (1983a) Hydration reaction and hardening of calcined clays and related minerals. I preliminary investigation on metakaolinite Cem Concr Res 13(2):259-266

Murat M (1983b) Hydration reaction and hardening of calcined clays and related minerals: II. Influence of mineralogical properties of the rawkaolinite on the reactivity of metakaolinite. Cem Concr Res 13(4): 511-518

Murat M, Comel C (1983) Hydration reaction and hardening of calcined clays and related minerals III. Influence of calcination process of kaolinite on mechanical strengths of hardened metakaolinite. Cem Concr Res 13(5):631-637

Ondruška J, Csáki Š, Trnovcová V, Štubňa I, Lukáč F, Pokorný J, Vozár L, Dobron̆ P (2018) Influence of mechanical activation on DC conductivity of kaolin. Appl Clay Sci 154:36-42

Orumwense OA, Forssberg E (1992) Superfine and ultrafine grinding - a literature survey. Miner Process Extr Metall Rev 11(1-2):107-127

Perrin-Sarazin F, Sepehr M, Bouaricha S, Denault J (2009) Potential of ball milling to improve clay dispersion in nanocomposites. Polym Eng Sci 49(4):651-665

Pérez-Rodriguez L, Del Villar MS, Sanchez-Soto P (1988) Effects of dry grinding on pyrophyllite. Clay Miner 23:399-410

Prokof'ev VY, Gordina N (2012) Comminution and mechanochemical activation in oxide ceramics technology. Glas Ceram 69(1-2):65-70 
Provis JL, Bernal SA (2014) Geopolymers and related alkali-activated materials. Annu Rev Mater Res 44:299-327

Rescic S, Plescia P, Cossari P, Tempesta E, Capitani D, Proietti N, Mecchi A (2011) Mechano-chemical activation: an ecological safety process in the production of materials to stone conservation. Procedia Engineering 21:1061-1071

Rose H, Sullivan R (1958) A treatise on the internal mechanics of ball, tube and rod mills, 1st edn. Chemical publishing Co., Inc., New York

Rumpf H (1973) Physical aspects of comminution and new formulation of a law of comminution. Powder Technol 7(3):145-159

Sabir B, Wild S, Bai J (2001) Metakaolin and calcined clays as pozzolans for concrete: A review. Cem Concr Compos 23(6):441-454

Sánchez RT, Basaldella E, Marco J (1999) The effect of thermal and mechanical treatments on kaolinite: characterization by XPS and IEP measurements. J Colloid Interface Sci 215(2):339-344

Sánchez-Soto PJ, Carmen Jiménez de Haro, María Pérez-Maqueda LA, Varona I, Pérez-Rodríguez JL (2000) Effects of dry grinding on the structural changes of kaolinite powders. J Am Ceram Soc 83(7): $1649-1657$

Sanchez-Soto P, Justo A, Perez-Rodriguez J (1994) Grinding effect on kaolinite-pyrophyllite-illite natural mixtures and its influence on mullite formation. J Mater Sci 29(5):1276-1283

Sánchez-Soto PJ, Wiewióra A, Avilés MA, Justo A, Pérez-Maqueda LA, Pérez-Rodríguez JL, Bylina P (1997) Talc from Puebla de Lillo. Spain II Effect of dry grinding on particle size and shape Applied Clay Science 12(4):297-312

Sandström A (2016) Mechanochemical treatment in metallurgy: An overview. In Conference in Minerals Engineering 2016: 02/02/2016-03/ $02 / 2016$

Scrivener KL (2014) Options for the future of cement. Indian Concr J 88(7):11-21

Shinozaki M, Senna M (1981) Effects of number and size of milling balls on the mechanochemical activation of fine crystalline solids. Ind Eng Chem Fundam 20(1):59-62

Souri A, Kazemi-Kamyab H, Snellings R, Naghizadeh R, Golestani-Fard F, Scrivener K (2015) Pozzolanic activity of mechanochemically and thermally activated kaolins in cement. Cem Concr Res 77:4759

Środoń J (2006) Identification and quantitative analysis of clay minerals. Developments in Clay Science 1:765-787

Stoch L, Wacławska I (1981) Dehydroxylation of kaolinite group minerals: I. kinetics of dehydroxylation of kaolinite and halloysite. J Therm Anal Calorim 20(2):291-304

Sugiyama K, Saito F, Waseda Y (1993) Effect of dry grinding on the structures and physical properties of pyrophyllite and talc by a planetary ball mill. Int J Soc Mater Eng Resour 1(1):140-147

Sugiyama K, Filio JM, Saito F, Waseda Y (1994) Structural change of kaolinite and pyrophyllite induced by dry grinding. Mineral J 17(1): $28-41$

Suryanarayana C, Ivanov E, A, V. (2001) The science and technology of mechanical alloying. Mater Sci Eng A 304:151-158

Suryanarayana C (2001) Mechanical alloying and milling. Prog Mater Sci 46(1):1-184

Takacs L (2000) Quicksilver from cinnabar: the first documented mechanochemical reaction. JOM 52(1):12-13

Takacs L (2004) M. Carey Lea, the first mechanochemist. J Mater Sci 39(16-17):4987-4993

Takahashi H (1959a) Effects of dry grinding on kaolin minerals. I. kaolinite. Bull Chem Soc Jpn 32(3):235-245

Takahashi H (1959b) Effects of dry grinding on kaolin minerals. II. kibushi-clay. Bull Chem Soc Jpn 32(3):245-251

Takahashi H (1959c) Wet grinding on kaolin minerals. Bull Chem Soc Jpn 32(4):381-387
Tkácová K (1989) Mechanical activation of minerals. Developments in mineral processing, volume 11, Elsevier. ISBN 0-444-98828-9 (Vol.11)

Tkačova K, Boldyrev V, Lyakhov N (1989) Energy dissipation during mechanical treatment of inorganic non-metallic substances. Paper presented at the Proceedings of the Indian National Science Academy 55:778-789

Tkáčová K, Heegn H, Števulová N (1993) Energy transfer and conversion during comminution and mechanical activation. Int $\mathrm{J}$ Miner Process 40(1-2):17-31

Tkácová K, Stevulova N (1987) Change in structure and enthalpy of carbonates and quartz accompanying grinding in air and aqueous environments. Powder Technol 52(2):161-166

Tole I, Habermehl-Cwirzen K, Rajczakowska M, Cwirzen A (2018) Activation of a raw clay by Mechanochemical process - effects of various parameters on the process efficiency and cementitious properties. Materials 11(10):1860

Urakaev FK, Boldyrev V (2000a) Mechanism and kinetics of mechanochemical processes in comminuting devices: 1 . Theory. Powder Technol 107(1):93-107

Urakaev FK, Boldyrev V (2000b) Mechanism and kinetics of mechanochemical processes in comminuting devices: 2. Applications of the theory. Powder Technol 107(3):197-206

Valášková M, Barabaszová K, Hundáková M, Ritz M, Plevová E (2011) Effects of brief milling and acid treatment on two ordered and disordered kaolinite structures. Appl Clay Sci 54(1):70-76

Vaughan F (1955) Energy changes when kaolin minerals are heated. Clay Miner 2:265-274

Vdović N, Jurina I, Škapin SD, Sondi I (2010) The surface properties of clay minerals modified by intensive dry milling - revisited. Appl Clay Sci 48(4):575-580

Vizcaíno L, Antoni M, Alujas A, Martirena F, Scrivener K (2015). Industrial manufacture of a low-clinker blended cement using lowgrade calcined clays and limestone as SCM: the cuban experience. Calcined clays for sustainable concrete, (pp. 347-358), Springer

Vizcayno C, De Gutierrez R, Castello R, Rodriguez E, Guerrero C (2010) Pozzolan obtained by mechanochemical and thermal treatments of kaolin. Appl Clay Sci 49(4):405-413

Volzone C, Aglietti E, Scian A, López JP (1987) Effect of induced structural modifications on the physicochemical behavior of bentonite. Appl Clay Sci 2(2):97-104

Weichert R, Schönert K (1973). About temperature and light emission at the fast crack propagation. In $I C F 3$, Munich (Germany)

Zhang Q, Tongamp W, Saito F (2011) Mechanochemical synthesis of kaolin-KH2PO4 and kaolin-NH4H2PO4 complexes for application as slow release fertilizer. Powder Technol 212(2):354-358

Yang H, Yang W, Hu Y, Du C, Tang A (2005) Effect of mechanochemical processing on illite particles. Part Part Syst Charact 22(3):207-211

Yoshimoto S, Ohashi F, Kameyama T (2005) Insertion of polypyrrole chains into montmorillonite galleries by a solvent-free mechanochemical route. Macromol Rapid Commun 26(6):461-466

Yoshimoto S, Ohashi F, Ohnishi Y, Nonami T (2004) Synthesis of polyaniline-montmorillonite nanocomposites by the mechanochemical intercalation method. Synth Met 145(2):265-270

Zbik M, Smart RSC (2005) Influence of dry grinding on talc and kaolinite morphology: inhibition of nano-bubble formation and improved dispersion. Miner Eng 18(9):969-976

Publisher's note Springer Nature remains neutral with regard to jurisdictional claims in published maps and institutional affiliations. 